\title{
DUMMY CB SEBAGAI ALAT SIMULATOR KUBIKEL UNTUK PEMELIHARAAN PREVENTIF DAN KOREKTIF GUNA MENGURANGI FREKUENSI PADAM PENYULANG 20 KV (APLIKASI PADA SISTEM SCADA 20 KV PT.PLN (PERSERO) APD JATENG \& DIY)
}

\author{
Meira Dwi Primanto, Priyo Sasmoko \\ Program Studi Diploma III Teknik Elektro \\ Fakultas Teknik Universitas Diponegoro
}

\begin{abstract}
Meira Dwi Primanto, Priyo Sasmoko, in paper dummy CB as cubicle simulator for preventive and corrective maintenance to reduce off frequency $20 \mathrm{KV}$ feeders (20 KV scada system at APD Central Java and Yogyakarta) explain that in 2013, the APD PT.PLN Central Java and Yogyakarta are conducting integration to SCADA at $20 \mathrm{KV}$ feeders in distribution substation. For the next stage has been installed SCADA maintenance should be done periodically. Maintenance can be planned or due to interference with the SCADA system. Maintenance is usually done by the team must perform SCADA Distribution feeder outages and transfer of the load. In the installation of equipment, SCADA team should get a working permit to shut down the feeder, and to transfer the load to another feeder, so that the work has to get permission. SCADA systems are already installed requires maintenance to keep the system reliability. When maintenance SCADA, feeders should be extinguished, whereas for medium voltage customers such as factories, hospitals, and airports should always be channeled electrical energy. Feeder outages and load Delegation KWH lost causes. To the authors attempt to provide solutions that can overcome the missing KWH with a tool innovations made. The author makes a tool such as a dummy circuit breaker simulator $20 \mathrm{KV}$ cubicles. This tool serves Especially when employees perform maintenance or investigation SCADA Disorders, which aims for $20 \mathrm{KV}$ feeders should not be extinguished when performing preventive and corrective maintenance. So the number of frequency of feeder outages can be reduced.
\end{abstract}

Keywords : Dummy Circuit Breaker, 20 KV PMT, SCADA maintenance.

\section{PENDAHULUAN \\ Latar Belakang}

Di tahun 2013, PT.PLN APD Jateng \& DIY sedang melaksanakan integrasi SCADA pada penyulang $20 \mathrm{KV}$ di Gardu Induk. Dalam pemasangan peralatan, tim SCADA harus mendapatkan working permit untuk mematikan feeder dan melimpahkan beban ke feeder lain, sehingga pekerjaan tersebut sudah terencana. Sistem SCADA yang sudah terpasang memerlukan pemeliharaan untuk menjaga keandalan sistem. Saat pemeliharaan SCADA, penyulang harus padam, padahal untuk pelanggan tegangan menengah seperti pabrik,rumah sakit, dan bandara harus selalu tersalur energi listrik. Padamnya penyulang dan Pelimpahan beban tersebut menyebabkan KWH hilang. Untuk itu penulis mencoba membuat sebuah alat inovasi agar penyulang tidak harus padam / dilimpahkan ketika pemeliharaan sistem SCADA. Alat ini bertujuan agar Penyulang tetap beroperasi disaat pemeliharaan preventif dan korektif / investigasi gangguan pada sistem SCADA gardu induk.

Pemeliharaan preventif dilaksanakan untuk mencegah terjadinya kerusakan peralatan secara tiba-tiba dan juga dapat mempertahankan unjuk kerja yang optimum sesuai unsur teknisnya. Kegiatan ini dilaksanakan secara berkala dengan berpedoman kepada: Instruction Manual dari
Pabrik, Standard yang ada (IEC, IEEE, dll) dan pengalaman operasi di lapangan. Pemeliharaan ini disebut juga dengan pemeliharaan berdasarkan waktu (Time Base Maintenance). Sedangkan Pemeliharaan korektif dilaksanakan setelah terjadi kerusakan atau pemeliharaan yang sifatnya darurat.

Tujuan berikut :

Tujuan dari penelititan ini adalah sebagai

- Merealisasikan alat dummy circuit breaker sebagai simulator kubikel minimum yang berfungsi untuk membantu dalam pemeliharaan sistem SCADA.

- Frekuensi padam penyulang $20 \mathrm{KV}$ disaat melakukan pemeliharaan sistem SCADA dapat dikurangi dengan menggunakan alat dummy CB. Sehingga KWH hilang yang diakibatkan dari padamnya penyulang tidak terjadi.

- Keadaan peralatan device Kubikel seperti RTU dan IED Relay Proteksi terpantau secara real time dari HMI SCADA secara normal.

- Dapat melakukan investigasi gangguan pada peralatan utama / pendukung sistem SCADA dengan mudah, yaitu dengan melacak gangguan dengan alat dummy CB. 
- $\quad$ Efesiensi waktu untuk pekerjaan pemeliharaan SCADA dari petugas PLN.

\section{Batasan Masalah}

- $\quad$ Pemeliharaan pada sistem SCADA feeder 20 KV.

- $\quad$ Pengoperasian alat dummy CB.

- Fungsi alat dummy CB untuk mengurangi frekuensi padam penyulang $20 \mathrm{KV}$ saat pemeliharaan sistem SCADA sehingga tidak terjadi KWH hilang.

- Penggunaan alat dummy CB pada investigasi gangguan pada sistem SCADA kubikel 20 KV.

\section{DASAR TEORI}

\section{Pengertian SCADA}

SCADA ( supervisory control and data acquisition ) adalah sistem yang dapat memonitor dan mengontrol suatu peralatan atau sistem dari jarak jauh secara real time. SCADA berfungsi mulai dari pengambilan data pada Gardu Induk atau Gardu Distribusi, pengolahan informasi yang diterima, sampai reaksi yang ditimbulkan dari hasil pengolahan informasi. Secara umum fungsi dari sistem SCADA adalah :

- Penyampaian data

- $\quad$ Proses kegiatan dan monitoring

- Fungsi kontrol

- Perhitungan dan pelaporan.

\section{Operasi \& Pemeliharaan SCADA}

Pengoperasian dan pemeliharaan peralatan sistem SCADA harus mengacu kepada dokumendokumen terkait misalnya Manual Book, Introduction Book atau Installation Workbook.

\section{Tujuan pemeliharaan}

Pemeliharaan adalah suatu pengawasan atau kegiatan yang dilakukan terhadap peralatan agar peralatan tersebut dapat beroperasi normal, optimal, andal dan memenuhi standar kinerja. Dalam hal ini kegiatan pemeliharaan yang dimaksudkan adalah pemeliharaan peralatan SCADA dan telekomunikasi. Tujuan dari pemeliharaan ini adalah untuk menjamin kontinuitas operasional dan pengoptimalan peralatan SCADA dan telekomunikasi, antara lain:

- Untuk meningkatkan reliability, availability dan efisiensi;

- Untuk mempertahankan lifetime peralatan;

- Untuk mengidentifikasi masalah dan mencegah masalah yang lebih besar.

\section{Jenis pemeliharaan}

Pemeliharaan dapat dibagi menjadi tiga jenis pemeliharaan, yaitu:

- Pemeliharaan preventive

Pemeliharaan preventive dilaksanakan untuk mencegah terjadinya kerusakan peralatan secara tiba-tiba dan juga dapat mempertahankan unjuk kerja yang optimum sesuai unsur teknisnya. Kegiatan ini dilaksanakan secara berkala dengan berpedoman kepada: Instruction Manual dari Pabrik, Standard yang ada (IEC, IEEE, dll) dan pengalaman operasi di lapangan. Pemeliharaan ini disebut juga dengan pemeliharaan berdasarkan waktu (Time Base Maintenance).

- $\quad$ Pemeliharaan predictive

Pemeliharaan predictive dilaksanakan dengan mengacu pada kondisi-kondisi tertentu. Kondisi tertentu yang dimaksud adalah parameter-parameter teknis dari peralatan yang tidak terpenuhi. Pemeliharaan ini disebut juga dengan pemeliharaan berdasarkan kondisi (Condition Base Maintenance).

- Pemeliharaan corrective

Pemeliharaan corrective dilaksanakan setelah terjadi kerusakan atau pemeliharaan yang sifatnya darurat.

\section{Dummy Circuit Breaker (Dummy CB)}

Blok diagram Dummy Circuit Breaker yang dilengkapi IED Relay Proteksi dan Meter Berbasis SCADA

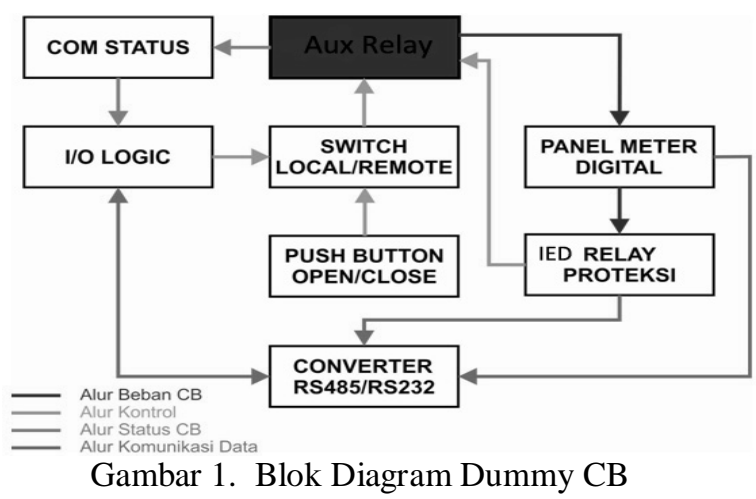

Sistem yang dibuat dapat dijabarkan dalam beberapa blok sistem, yaitu :

- Rangkaian Auxiliary relay

Auxelary relay $C B$ berfungsi sebagai pembuka maupun pemutus beban yang mengalir kerangkaian, termasuk arus hubung singkat yang disimulasikan dari current injector/test relay.

- $\quad$ Panel Meter Digital

Panel meter berfungsi untuk melakukan pengukuran voltage/tegangan, ampere/arus, watt/daya, hz/frekuensi, cos phi yang mengalir pada Dummy $C B$ yang diinjeksikan dari current injector/test relay. Informasi dari sinyal input berupa data pengukuran kemudian ditampilkan dalam format digital serta dengan port komunikasi yang tersedia data pengukuran dikirimkan ke Control Center untuk ditampilkan pada HMI (Human Machine Interface). 
- IED Relai Proteksi

Berfungsi untuk sebagai pemantauan dan pengukuran serta akan bekerja secara otomatis untuk mentripkan Dummy CB dan atau mengirimkan alarm ke SCADA apabila terjadi perubahan/indikasi gangguan yang diakibatkan dari perubahan besarnya beban yang melebihi settingan relai yang dialirkan dari current injector/test relay.

- $\quad$ Switch Local Remote

Pada kubikel sesungguhnya Switch Local Remote berfungsi sebagai governoor yaitu sebagai pengaman untuk memperkecil kesalahan manuver saat dilakukan pemeliharaan. Apabila dilakukan pekerjaan pada kubikel Switch harus diposisikan Local agar tidak bisa dikontrol dari HMI SCADA dan kesalahan manuver-pun dapat diperkecil. Pembacaan Status Local Remote juga dapat dilihat pada HMI SCADA menggunakan bantuan device I/O Logic.

- Push Button Open/Close

Berfungsi untuk melaksanakan perintah manual Open/Close Dummy CB secara langsung. Untuk dapat melakukan perintah manual, Switch control harus dalam keadaan local.

- Common Status

Berfungsi sebagai common terminal pembacaan status Open/Close Dummy CB untuk ditampilkan pada panel maupun dibaca oleh I/O Logic.

- $\quad$ I/O Logic

I/O Logic berfungsi sebagai pembacaan status Open/Close Dummy CB yang diambil dari common status yang kemudian dikirimkan menggunakan kabel komunikasi untuk ditampilkan di HMI pada Control Center, serta untuk meneruskan perintah Control Open/Close ke Dummy CB dari HMI SCADA dengan bantuan relay bantu.

- Converter RS485/RS232

Port komunikasi RTU Concetrator menggunakan kabel komunikasi RS232 sedangkan pada device-device Dummy CB komunikasinya menggunakan kabel RS-485 oleh karena itu diperlukan converter agar dapat terhubung satu sama lain. RS adalah singkatan dari Recommended Standard kedua jenis RS tersebut merupakan physical layer (Hardware) dari Layer pertama di OSI Model yang pada intinya pada phisycal layer bagaimana hardware tersebut mengubah data menjadi sinyal elektrik dan juga sebaliknya mengubah sinyal elektrik menjadi data.

\section{Cara Kerja Dummy CB}

Berikut penjelasan sistem kerja Dummy CB, Gambar keseluruhan rangkaian terdapat pada Gambar 2.
- Dummy CB akan berada pada kondisi standby ketika mendapat 3 jenis supply tegangan yang berbeda besarannya yaitu 220 Vac, 110 Vdc, dan 24 Vdc. Supply 220 Vac digunakan untuk power input Panel Meter Digital GAE EMG30, source input untuk metering tegangan, dan untuk menghidupkan LED panel indikator. Supply 110 Vdc digunakan sebagai power input IED Relai MICOM P123, penggerak coil Dummy dan Common status. Sedangkan supply 24 Vdc digunakan sebagai power input pada I/O Logic Moxa R2110 dan penggerak coil relai bantu I/O Logic.

- Untuk melakukan fungsi control Open/Close Dummy CB dapat dilakukan dengan 2 cara yaitu dari Push Button yang terletak pada Box Panel dan dapat pula dilakukan melalui HMI SCADA melalui I/O Logic. Dengan dipasangnya Switch Local/Remote kedua cara diatas tidak dapat dilakukan secara bersamaan dan hanya akan bekerja pada salah satu cara, kontrol hanya dapat dilakukan dari SCADA (saat switch posisi remote) atau hanya dari panel push button (saat switch posisi local).

- Kontrol secara remote dilakukan dari HMI SCADA yang diteruskan oleh perangkat I/O Logic yang kemudian output kontrol dari terminal digital output menggerakan coil relay bantu untuk melakukan fungsi kontrol pada Dummy.

- Injeksi beban dari current injector masuk ke contact Dummy yang kemudian dihubungkan ke panel meter digital untuk dibaca besaranya. Dari panel meter wiring beban dirangkai seri ke relai proteksi Micom P123 untuk dianalisis besarannya. Apabila besaran beban melebihi settingan yang ditentukan otomatis relai akan bekerja untuk mengontak dan mentripkan Dummy.

- Kondisi pada peralatan Dummy dapat dimonitoring dari HMI SCADA menggunakan 3 device digital yang dikomunikasikan menggunakan RS485 yaitu I/O Logic untuk pembacaan status dan kontrol CB, Panel Meter Digital untuk metering besaran yang mengalir pada Dummy, dan IED Relai Proteksi untuk mendeteksi simulasi indikasi gangguan yang terjadi pada Dummy CB.

- $\quad$ Monitoring Dummy selain 3 device diatas juga membutuhkan perangkat pendukung lain dan proses yang panjang agar mampu berkomunikasi dengan HMI. Yang dapat digambarkan seperti pada blok diagram dibawah ini : 


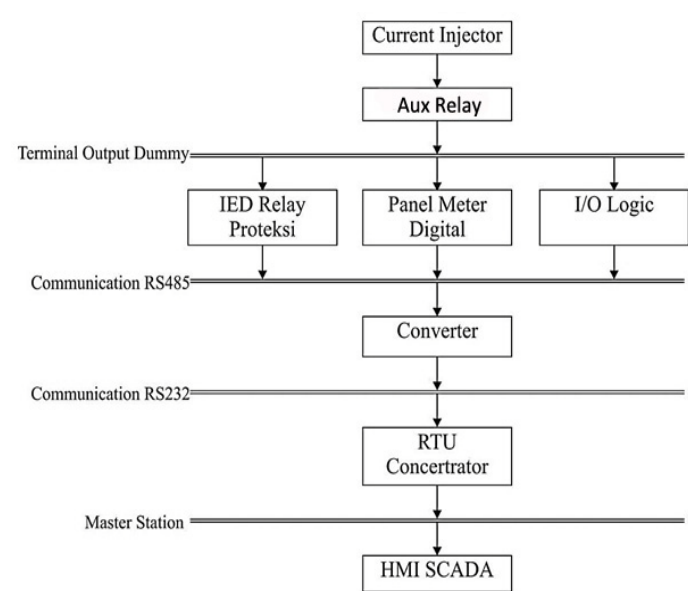

Gambar 2. Monitoring Dummy CB

\section{HASIL PENGAMATAN DAN PEMBAHASAN Gangguan Sistem SCADA}

Sistem SCADA tidak akan bisa ideal 100\%, karena sering adanya gangguan yang terjadi yang akan mempengaruhinya. Salah satu gangguan pada sistem SCADA adalah Out Of Scanning yang diakibatkan oleh Gangguan pada RTU. Semakin banyak populasi gangguan yang terjadi, maka secara signifikan akan mengurangi tingkat kehandalan jaringan distribusi yang berada di bawah kendali sistem SCADA. Jenis gangguan yang terjadi pada sistem SCADA dibedakan menjadi 2 :

- Gangguan yang sifatnya not available yaitu gangguan yang menyebabkan dispatcher tidak bisa melakukan Remote Control karena ketidaksiapan fasilitas remote yang ada di lokasi (GI, GH, CDS, DS) dan indikasi di monitor dispatcher menunjukkan adanya gangguan. Yang termasuk gangguan ini adalah OOS yang mengindikasikan bahwa fasilitas RC tidak dapat dipantau karena komunikasi antara pusat kontrol dengan RTU terputus

- Gangguan yang sifatnya available yaitu gangguan yang terjadi karena gagal RC (Remote Control), sebenarnya indikasi pada monitor di dispatcher tidak menunjukkan adanya gangguan namun ketika dilakukan remote control mengalami kegagalan.

Dalam pembahasan ini analisis yang dilakukan akan dibatasi pada kegagalan remote control akibat gangguan OOS (Out Of Scanning). Gangguan OOS dapat disebabkan oleh:

- Gangguan pada RTU

- Gangguan terhadap salah satu komponen Penyusunnya akan mempengaruhi performansi RTU sendiri, gangguan bisa terjadi pada card prosesor, card memori, card peripheral maupun pada software RTU.

- Gangguan pada Modem

- Gangguan pada Kabel Kontrol
Pada umumnya perawatan dilakukan sekaligus pada saat pemasangan dan pada saat terjadi gangguan, meskipun idealnya dilakukan minimal 1x per tahun.

\section{Percobaan Alat Dummy CB}

Penulis mendapatkan data KWH hilang yang di dapat dari data laporan dispatcher PT.PLN (Persero) APJ Purwokerto yang kemudian diolah. KWH hilang yang dialami adalah ketika terjadi pemeliharaan sistem SCADA yang mengakibatkan penyulang $20 \mathrm{KV}$ harus dilakukan pelimpahan beban. Dari data laporan tersebut, besarnya KWH hilang tergantung dari besarnya daya hilang dikalikan lama padam akibat pelimpahan beban. Berikut adalah rumus yang digunakan untuk menghitung data tabel:

$$
\begin{array}{ll}
\text { Daya Hilang }= & \sqrt{3} \times V \times I \times \operatorname{Cos} \emptyset \ldots . .(3.1) \\
\text { KWH Hilang }= & \frac{\sqrt{3} \times V \times I \times \operatorname{Cos} \emptyset \times t}{60} \ldots \ldots . . .(3.2) \\
\text { Keterangan }: & \begin{array}{l}
V=\text { Tegangan }(K V) \\
I=\text { Arus Beban }(\text { Ampere) }
\end{array} \\
& \text { Cos } \emptyset=0,8 \\
& t=\text { Lama Padam (Menit) }
\end{array}
$$

Lama padam adalah waktu yang terbuang ketika beban mulai dilimpahkan hingga beban berhasil dilimpahkan ke penyulang lain. Jadi yang dimaksud Dummy Circuit Breaker untuk mengurangi KWH hilang adalah benar. Karena Pada pelanggan jaringan tegangan menengah seperti Pabrik, rumah sakit, dan bandara, tersalurnya energi listrik sangatlah penting, artinya JTM sangat diusahakan untuk tidak padam. Maka dari itu, biasanya yang dilakukan PT.PLN (persero) saat pemeliharaan SCADA adalah melimpahkan beban ke penyulang lain. Tetapi pelimpahan beban tersebut juga merugikan PT.PLN karena dalam pelimpahan beban terjadi padam sesaat yang menyebabkan $\mathrm{KWH}$ hilang. Dan saat pelimpahan juga terjadi kemungkinan PMT bisa trip yang menyebabkan lamanya Penyulang tidak beroperasi, dan pelanggan mati karena penyulang yang dipelihara belum mendapat suplai tegangan dari feeder lain. Tetapi dengan adanya alat Dummy CB ini, kita tidak perlu melakukan Pelimpahan beban ataupun memadamkan penyulang kecuali dalam keadaan darurat. Jadi alat dummy CB sangat membantu dalam hal pemeliharaan dan investigasi gangguan pada sistem SCADA Gardu Induk.

Dengan adanya alat dummy CB, KWH hilang dapat diatasi dan tidak terjadi saat kita melakukan pemeliharaan SCADA. Karena PMT tidak dipadamkan dan tidak dilakukannya pelimpahan beban ke feeder lain. Uji Commissioning untuk control open / close juga tidak akan berpengaruh pada PMT aslinya. Karena Sistem komunikasi SCADA akan dihubungkan ke alat dummy CB saat pemeliharaan.

Selain itu manfaat yang lain adalah lebih mudahnya dalam membuat working permit untuk pemeliharaan SCADA, karena tidak perlu izin 
untuk memadamkan / melimpahkan beban feeder. Jumlah pegawai yang ikut dalam pekerjaan juga tidak terlalu banyak, karena petugas Rayon tidak perlu ke lapangan untuk melakukan pelimpahan beban pelanggan pada tiang ABsw.

Dengan adanya alat dummy CB ini tentu sangat menguntungkan, baik bagi PT.PLN (Persero) maupun pelanggan, karena listrik tidak padam dan kebutuhan dapat terpenuhi secara maksimal.

\section{PENUTUP}

\section{Kesimpulan}

- $\quad$ Alat dummy CB dapat mengurangi mengurangi frekuensi padam penyulang $20 \mathrm{KV}$ disaat pemeliharaan sistem SCADA, karena disaat uji coba Commissioning atau control open / close, hasil keluaran dapat dilihat pada dummy CB, sehingga tidak berpengaruh pada PMT asli kubikel, dan penyulang yang dipelihara tetap beroperasi. Sehingga dapat meminimalisir KWH hilang yang terjadi akibat pemadaman terencana.

- Dummy CB dapat di operasikan dalam posisi Local / Remote untuk mengurangi kesalahan manuver di saat pemeliharaan.

- Saat pengujian alat menggunakan inject arus/test relai, agar relai proteksi dan panel meter dapat membaca arus yang diterima, diperlukan setting parameter terlebih dahulu.

- Dummy CB dapat di-monitor dari HMI SCADA menggunakan 3 device digital yang dikomunikasikan menggunakan RS485 yaitu I/O Logic untuk pembacaan status dan kontrol CB, Panel Meter Digital untuk metering besaran yang mengalir pada Dummy, dan IED Relai Proteksi untuk mendeteksi simulasi indikasi gangguan yang terjadi pada Dummy CB.

Saran

- Wiring / pengkabelan diberi label agar saat terjadi kerusakan / gangguan alat dummy CB dapat diperbaiki dengan mudah.

- Agar alat dapat bekerja secara optimal, maka diperlukan perawatan dan kalibrasi secara berkala yaitu untuk menguji apakah peralatan masih berfungsi dengan baik dan dapat digunakan untuk pemeliharaan.

\section{DAFTAR PUSTAKA}

1. Heijer, P.C. den; \& Tolsma, R. 1988. Komunikasi Data. Lily Wibisono (Penerjemah). Jakarta: PT Elex Media Komputindo kelompok Gramedia.

2. Kelompok Bidang SCADA PT PLN (Persero), 2009 , SPLN S7-001:2008 tentang Operasi
\& Pemeliharaan Sistem SCADA, PT.PLN (Persero) Pusat, Jakarta.

3. PT.PLN (Persero) Distribusi Jawa Tengah \& DIY Area Pengaturan Distribusi Semarang, 2011 , Standar Operasional Prosedur (SOP) Integrasi SCADA Pada Penyulang 20 KV.

4. PT.PLN (Persero) Area Pengatur Distribusi Jateng \& DIY, 2010 , Penanganan Gangguan \& Pemeliharaan Relay Proteksi, Semarang.

5. PT.PLN (Persero) Pusat Pendidikan dan Pelatihan, 2008, Overview SCADA Distribusi, Semarang.

6. SCADA PT.PLN Jateng \& DIY , 2011, Buku SCADA, Edisi-01 Maret 2011, Semarang.

7. Sofyan, A. 2005. Analisis penyebab out of scanning pada SCADA akibat gangguan RTU. Jakarta : Jurusan Teknik Elektro, FTI, Institut Sains dan Teknologi Nasional. 
Tabel 1. Data laporan dispatcher bulan februari 2013 di APJ Purwokwerto (sebelum ada dummy CB)

\begin{tabular}{|c|c|c|c|c|c|c|c|c|c|c|}
\hline No & Tgl & Gi & $\begin{array}{c}\text { Penyula } \\
\text { ng } \\
\text { Dipeliha } \\
\text { ra }\end{array}$ & $\begin{array}{c}\text { Jam } \\
\text { Pelimp } \\
\text { ahan }\end{array}$ & $\begin{array}{c}\text { Jam } \\
\text { Beban } \\
\text { Dilimp } \\
\text { ahkan }\end{array}$ & $\begin{array}{c}\text { Lama } \\
\text { Pada } \\
\text { m }\end{array}$ & A & $\mathbf{K v}$ & $\begin{array}{c}\text { Daya } \\
\text { Hilang }\end{array}$ & $\begin{array}{c}\text { Kwh } \\
\text { Hilang }\end{array}$ \\
\hline 1 & 11-Feb-13 & PURBALINGGA & PBG01 & $8: 27$ & $8: 39$ & 12 & 263 & 20.4 & 7434.021 & 1486.80 \\
\hline 2 & $11-F e b-13$ & PURBALINGGA & PBG02 & $9: 49$ & $10: 01$ & 12 & 92 & 20.3 & 2587.747 & 517.55 \\
\hline 3 & $12-F e b-13$ & PURBALINGGA & PBG03 & $8: 10$ & $8: 17$ & 7 & 55 & 20.2 & 1539.402 & 179.60 \\
\hline 4 & $12-F e b-13$ & PURBALINGGA & PBG04 & $8: 40$ & 9:01 & 21 & 174 & 20.2 & 4870.107 & 1704.54 \\
\hline 5 & 13-Feb-13 & PURBALINGGA & PBG05 & $8: 30$ & 8:49 & 19 & 139 & 20.5 & 3948.267 & 1250.28 \\
\hline 6 & $18-F e b-13$ & DIENG & DNG01 & $8: 24$ & $8: 35$ & 11 & 32 & 20.4 & 904.5197 & 165.83 \\
\hline 7 & 18-Feb-13 & DIENG & DNG02 & 9:01 & $9: 12$ & 11 & 234 & 20.1 & 6517.031 & 1194.79 \\
\hline 8 & 19-Feb-13 & DIENG & DNG03 & $8: 43$ & $8: 50$ & 7 & 25 & 20.3 & 703.192 & 82.04 \\
\hline 9 & $19-F e b-13$ & DIENG & DNG04 & $9: 23$ & 9:35 & 12 & 153 & 20.3 & 4303.535 & 860.71 \\
\hline
\end{tabular}

Tabel 2. Data laporan dispatcher bulan April 2013 di APJ Purwokwerto (setelah ada dummy CB)

\begin{tabular}{|c|c|c|c|c|c|c|c|c|c|c|}
\hline No & Tgl & Gi & $\begin{array}{c}\text { Penyula } \\
\text { ng } \\
\text { Dipelih } \\
\text { ara }\end{array}$ & $\begin{array}{c}\text { Jam } \\
\text { Pelimpah } \\
\text { an }\end{array}$ & $\begin{array}{c}\text { Jam } \\
\text { Beban } \\
\text { Dilimp } \\
\text { ahkan }\end{array}$ & $\begin{array}{c}\text { Lama } \\
\text { Pada } \\
\text { m }\end{array}$ & $\mathbf{A}$ & $\mathbf{K v}$ & $\begin{array}{c}\text { Daya } \\
\text { Hilang }\end{array}$ & $\begin{array}{l}\text { Kwh } \\
\text { Hilang }\end{array}$ \\
\hline 1 & 15-Apr-13 & PURBALINGGA & PBG 01 & - & - & - & 134 & 20.0 & 0 & 0 \\
\hline 2 & 15-Apr-13 & PURBALINGGA & PBG 02 & - & - & - & 168 & 20.3 & 0 & 0 \\
\hline 3 & 15-Apr-13 & PURBALINGGA & PBG 03 & - & - & - & 134 & 20.6 & 0 & 0 \\
\hline 4 & 16-Apr-13 & PURBALINGGA & PBG 04 & - & - & - & 140 & 19.8 & 0 & 0 \\
\hline 5 & 16-Apr-13 & PURBALINGGA & PBG 05 & - & - & - & 127 & 19.8 & 0 & 0 \\
\hline 6 & 18-Apr-13 & DIENG & DNG 02 & - & - & - & 118 & 20.4 & 0 & 0 \\
\hline 7 & 18-Apr-13 & DIENG & DNG 03 & - & - & - & 240 & 20.1 & 0 & 0 \\
\hline 8 & 19-Apr-13 & DIENG & DNG 04 & - & - & - & 160 & 20.2 & 0 & 0 \\
\hline 9 & 19-Apr-13 & DIENG & DNG 05 & - & - & - & 148 & 20.0 & 0 & 0 \\
\hline
\end{tabular}

Tabel 3. Perbandingan Sebelum dan Sesudah adanya alat dummy CB

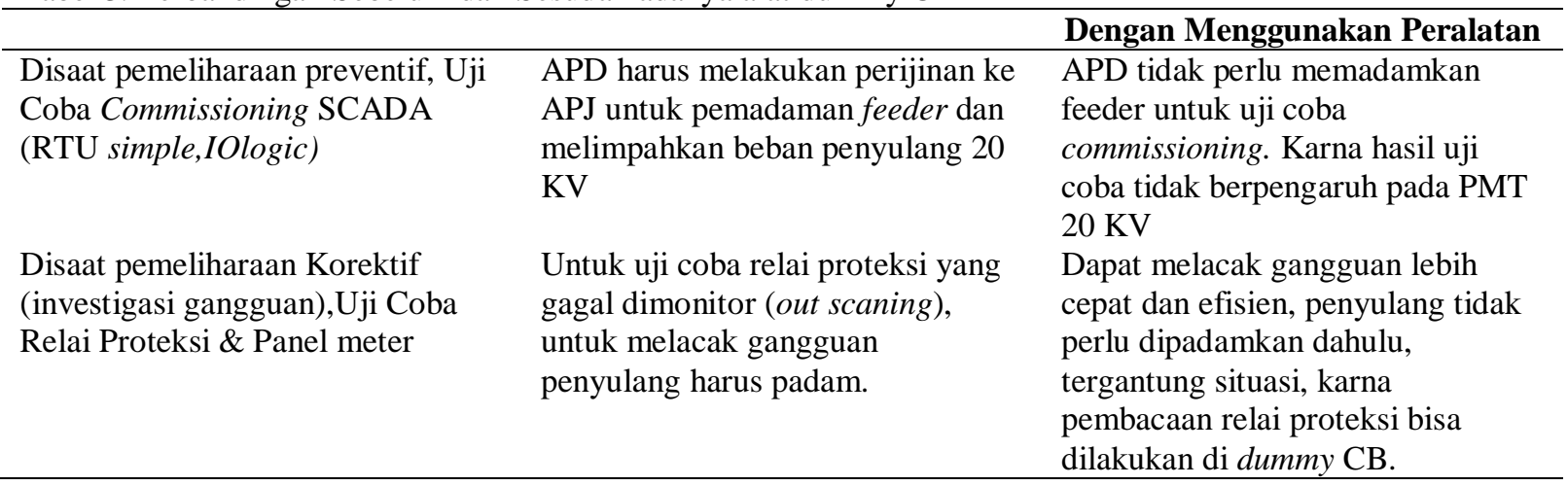

